\title{
Italy pulls plug on unproven cancer 'cure'
}

[MUNICH] The Italian Ministry of Health, forced by public pressure to conduct clinical trials on the controversial 'Di Bella' cancer treatment, announced last week that patients with the types of cancer tested in the trials will no longer be reimbursed for such treatment.

This follows the news that the trials have shown the therapy to be of no clinical value. None of the 134 patients in four clinical protocols showed any indication of remission during three months of treatment, and three-quarters of them have died.

But support for the therapy is still being voiced from many quarters, most strongly from right-wing politicians hoping to benefit politically from its popular backing.

The therapy, designed by physician Luigi Di Bella, is a cocktail of natural products and the expensive drug somatostatin, sometimes also with a low dose of the chemotherapeutic agent cyclophosphamide. Di Bella, now in his mid-80s, claims to have cured thousands of patients in the past couple of decades (see Nature 391, 217; 1998).

Controversy arose when his many followers began to demand that the government pay for the treatment, which costs up to US\$6,500 per month. The health ministry initially refused even to conduct clinical trials with the therapy - a prerequisite for reimbursable drugs - because of the lack of a scientific basis for its effectiveness.

When the strength of public support for Di Bella forced the ministry's hand earlier this year, minister Rosy Bindi approved ten tightly designed multicentre trials in different types of cancer.

Di Bella and his supporters, known as Di Bellists, have refused to accept that the therapy does not work, despite the fact that another trial conducted by the Di Bellafriendly government of Lombardia, whose results were announced a few weeks ago, had proved similarly negative.

Di Bella formally approved the protocols of the government-sponsored trials before they began. But after the results of the first four protocols had been published- the remaining six will be completed by October - he said he had not read the documents before he signed them. He also insists that the protocols do not correspond exactly to his therapy, and that the trials are therefore not valid.

The local judge from Lecce in Puglia, who first ordered that the state pay for a patient to be treated with Di Bella therapy, has set up his own inquiry into the validity of the trials, and has ordered Giuseppe Benegiano, director of the Higher Institute of Public Health in Rome, which is coordinating the trials, to testify this week.

Benegiano, who has been inundated with calls from people claiming that the trials were designed only to "count the dead", has published a request for those cancer sufferers who claim to have been cured to come forward for assessment, "so that we can also count the living".

The issue is receiving close attention in top political circles. Prime minister Romano Prodi has publicly welcomed the "clarity" of the results of the trials, while his political opponents in right-wing parties such as Forza Italia, hoping to gain populist support, have accused the centre-left government of wanting to discredit Di Bella to avoid having to pay for the treatment.

Benegiano says he hopes that public opinion, which has been staunchly behind Di Bella, will be swayed by the mounting evidence - including trials conducted by Di Bellists themselves - that the treatment does not work. "But it will take some time, because the Di Bellists seem incapable of taking no for an answer," he says. Alison Abbott

\section{Germany faces physics graduate shortage as students turn away}

[MUNICH] The number of new physics graduates in Germany is expected to fall by almost two-thirds in the next five to six years, according to the German Conference of Physics Faculties (KFP).

Konrad Kleinknecht, a spokesman for the KFP, warns that the decreased output will be well below the demands of industry and research. Gerhard Soff, vice-dean of the physical faculty of the University of Dresden, says university research could be in danger, as financing is linked to student numbers.

The news closely follows a similar fall in enrolment in chemistry courses (see Nature $388,707 ; 1997)$, although general student numbers will have fallen by only 10 per cent.

Concern over employment prospects and the German phenomenon of Technologiefeindlichkeit (aversion to technology) are the most widely cited reasons for this.

The closing of the former East Germany's Academy of Sciences in 1990 threw many physicists and chemists out of work, against a background of world recession and loss of business for companies supplying military contractors after the end of the cold war.

Recently the situation has changed. "Graduates are practically snatched away from universities at the moment," says Kleinknecht. Industry needs young physicists in traditional areas such as semiconductor technology and optics, as well as in new fields such as information technology and software design, he says. Management consulting and insurance companies are employing growing numbers of graduates. But, he adds, scepticism about new technologies is keeping many talented young people from choosing physics.

Bernd Fischer, a personnel officer at Siemens, reflects a widespread feeling among physics professors and in industry that school teaching is excessively influenced by

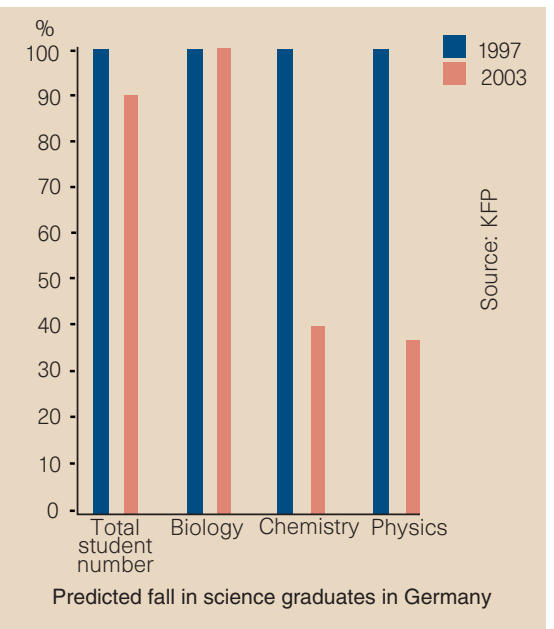

Figures show exact sciences falling from favour. "the 1968 generation of teachers", who are not interested in science.

Ten scientific societies in Germany have formally requested science ministries in the 16 Länder (states) to take steps to increase and improve the teaching of mathematics and natural sciences at high schools, and to ensure that more pro-science teachers are employed.

The KFP is optimistic that campaigns can influence public opinion. The fact that biology has not lost popularity is at least partly ascribed to an energetic government campaign to promote biotechnology.

But Josef Langer, general secretary of the German University Rectors Conference, points out that disproportionate falls in student numbers in physics or chemistry are not unique to Germany. "The trend has already been observed in other northern European countries," he says. These include Austria, Belgium and the Netherlands.

A recent internal European Commission report notes the low status of science in some countries, but says the causes of falling enrolments are complex and "need a much deeper socio-cultural study". It says that education ministries, teachers and the media should work to improve the image of the natural sciences by emphasizing their positive effects on society. Annette Kloboucek 